This item was submitted to Loughborough's Research Repository by the author.

Items in Figshare are protected by copyright, with all rights reserved, unless otherwise indicated.

\title{
Computational pregnant occupant model, 'Expecting', for crash simulations
}

PLEASE CITE THE PUBLISHED VERSION

http://dx.doi.org/10.1243/09544070JAUTO1072

\section{PUBLISHER}

Sage / @ IMechE

\section{VERSION}

AM (Accepted Manuscript)

LICENCE

CC BY-NC-ND 4.0

\section{REPOSITORY RECORD}

Acar, B. Serpil, and David W. van Lopik. 2019. "Computational Pregnant Occupant Model, 'expecting', for Crash Simulations”. figshare. https://hdl.handle.net/2134/14958. 


\section{Computational Pregnant Occupant Model 'Expecting' for Crash Simulations}

\section{B Serpil Acar and D van Lopik}

Department of Computer Science, Research School of Informatics, Loughborough University, UK

Abstract: A computational model of the pregnant occupant, capable of simulating the dynamic response to acceleration impacts is introduced. The occupant model represents $a 5^{\text {th }}$ percentile female at around $38^{\text {th }}$ weeks of pregnancy. A finite element uterus and multi-body fetus is integrated into an existing female model to incorporate pregnant female anthropometry.

The complete model, 'Expecting', is used to simulate a range of frontal impacts of increasing severity from $15-45 \mathrm{kph}$. Three levels of occupant restraint, completely unrestrained, 3-point seatbelt and 3-point seatbelt with an airbag, are investigated. Strains developed in the uterus due to loading from the seatbelt and steering wheel are presented, along with an analysis of stress distribution due to inertial loading of the fetus on the uterus.

The unrestrained cases are shown to be the most dangerous to the fetus, due to high interaction with the vehicle steering wheel at the level of the placenta. The use of a 3-point seatbelt together with a driver airbag appears to offer the greatest protection to the fetus.

Keywords: Modelling, crash, seatbelt, airbag, safety, pregnant, fetus, injury. 


\section{INTRODUCTION}

\subsection{Background}

During pregnancy, the female body undergoes many changes. These changes are wide ranging, and the presence of a fetus, along with the unique geometry of the pregnant woman, can negatively impact on both the comfort and safety of the pregnant occupant while driving or travelling in today's vehicles. The level of exposure of pregnant women to automobile accidents is on the increase, due to more women driving and driving longer distances, than ever before [1]. It has been shown in the literature that $6-7 \%$ of all pregnancies are affected by trauma [2], with motor-vehicle accidents being the leading cause of accidental fetal mortality worldwide [3]. For the United States it has been estimated that around 130,000 women in the second half of pregnancy are involved in car accidents each year. Of these, around 30,000 will sustain treatable injuries, while approximately 160 will die. From those that survive, between 300-3800 will result in fetal loss [4].

The safety of occupants and their risk of injury in automobile accidents are typically evaluated and assessed using anthropometric test devices (ATDs), either physical or computational, together with real-world crash data and experimental work with cadavers or human volunteers. In the case of pregnant women, real word crash data is limited and tests with pregnant volunteers or cadavers are not viable. Some experimental work was conducted in the late 1960s and early 1970s to evaluate the effectiveness of the three-point seatbelt for pregnant women, using pregnant baboons as surrogates $[5,6]$.

In terms of ATDs, two pregnancy inserts have been developed for use with the Hybrid III small female dummy [7, 8], the second of which is now a commercially available tool. This second-generation insert of the 'MAMA2B' comprises a water filled bladder, which is the size of a 30th week pregnant uterus, covered by neoprene 'skin' jacket. No placenta or fetus was included in the model. However, pressure in the bladder was measured and related to fetal injury risk, to allow the assessment of restraint systems on fetal survivability. 
Performing tests with a physical crash test dummy can be both costly and time consuming, with many limitations in terms of achieving an accurate human-like response. Computational modelling on the other hand offers an economical solution, with human body models enabling a greater level of anatomical detail, potentially offering an improved biofidelic response over ATDs. Moorcroft et al [9] have developed a computational pregnant female model within the crash analysis software package MADYMO. The model consists of a FE placenta and uterus and filled with amniotic fluid and integrated into an existing $5^{\text {th }}$ percentile female occupant model available within the MADYMO software. The decision of not to include a fetus in the pregnant occupant model in their design was based on the findings of Rupp et al [8] which hypothesized five injury mechanisms and concluded that the mechanisms of injury that ultimately leads to fetal loss is independent of the fetus itself. As with the MAMA2B, the computational model represents a woman at around the $30^{\text {th }}$ week of gestation in terms of abdominal size and shape. The model was used to predict the risk of injury in various crash scenarios with a range of restraint configurations.

The significant mass $(3.3 \mathrm{~kg})$ of the considerably solid fetus during the later stages of pregnancy almost fills the entire volume of uterus but is free to move during an impact, only constrained by the boundaries of the uterus. The fetus has therefore the potential to affect the entire dynamic response to impact. Hence the magnitude and location of the forces exerted by the solid fetus and the consequent stresses and strains would be significantly different than those exerted by the fluid alone. Hence the lack of any representation of a fetus in recent models, both physical and computational, warrants further investigation in this area.

\subsection{Overview of pregnant anatomy}

Pregnancy begins at fertilization with fetal development commencing at around the start of the ninth week of gestation. The duration of pregnancy is approximately around 40 weeks, and for convenience is considered as three integrated trimesters. The following information about the normal fetal development during the trimesters is taken from England [10]. The fist trimester is the period of embryonic and early 
fetal development; by the end of the $12^{\text {th }}$ week the fetus will be around $75 \mathrm{~mm}$ in length with a weight of approximately $14 \mathrm{~g}$. During the second trimester the organs and organ systems of the fetus complete their development and by the end of the $28^{\text {th }}$ week the fetus will have increased in weight to roughly $0.64 \mathrm{~kg}$. Over the final trimester the organ systems become functional and a rapid increase in size and weight of the fetus is seen reaching around $3.3 \mathrm{~kg}$ at term.

The general anatomy of the pregnant abdomen at term is depicted in Fig. 1, as in $95 \%$ of all pregnancies the fetus is shown in an upside-down position with its head downwards and back against the anterior uterine wall. The uterus is a muscular organ that encloses the fetus, increasing in size to accommodate the fetus as it develops. As pregnancy proceeds, the uterus expands out of the pelvic basin displacing other abdominal organs upward, with the top of the uterus (the uterus fundus) reaching the level of the xiphisternum by the $36^{\text {th }}$ week of gestation [11]. The uterus is attached at the cervix to the pelvis and sacrum via ligaments, but is otherwise unattached in the abdominal cavity. From around the $16^{\text {th }}$ week onwards the uterus makes contact with the anterior abdominal wall and the lumbar and sacral spines. Also contained within the uterus are the placenta and amniotic fluid. The amniotic fluid surrounds the fetus allowing free movement and physically cushions the embryo as it develops. At term the volume of amniotic fluid relative to that of the fetus is at its lowest, around $10 \%$ of the uterine volume. Amniotic fluid is about $98-$ $99 \%$ water [12].

The placenta is a large vascular organ that covers approximately a quarter of the inner surface of the uterus. In around $80 \%$ of pregnancies the placenta is located in the upper region of the uterus near the fundus [13]. The placenta attaches to the internal surface of the uterus via small finger-like protrusions from the surface of the placenta known as microvilli, as well as connecting the two structures; this uteroplacental interface (UPI) facilitates nutrient transportation to the fetus. 


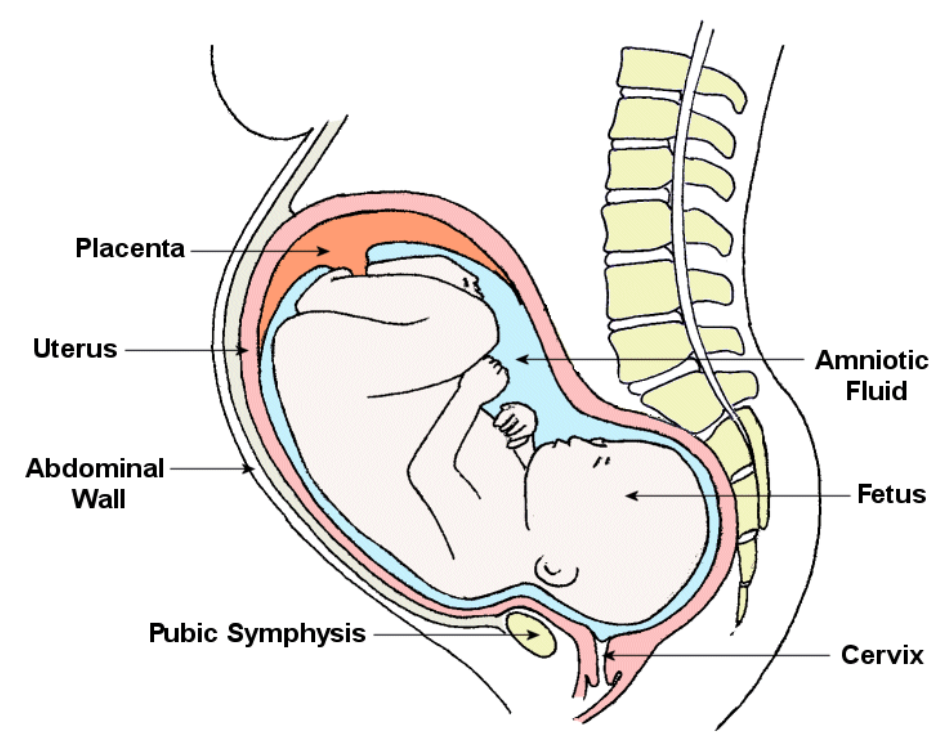

Fig 1 Anatomy of the pregnant abdomen.

\subsection{Injuries to the pregnant occupant}

The risks to the fetus in the case of an automobile impact have been described in medical studies as being; placental abruption [14,15], maternal death [16], direct fetal injury [17], fetomaternal transfusion [18], onset of labour and preterm delivery [19]. It has been estimated that placental abruption accounts for around $50-70 \%$ of all fetal deaths in motor vehicle accidents [20]. Placental abruption is where the placenta becomes partially or completely detached from the inner surface of the uterus, due to failure of the utero-placental interface. Pearlman [2] discussed that due to differing tissue characteristics between the uterus and placenta, large deformation of the uterus can create a shearing effect at the UPI, leading to separation of the two structures. Quasi-static testing of uterus-placenta tissue samples has found that the UPI fails when a strain of around $60 \%$ is reached in the uterus at the placental location [20].

Direct injuries to the fetus are less common, occurring in less than $1 \%$ of automobile accidents [4]. In such cases, the fetus sustains a direct loading injury as the protective cavity of the mothers abdominal-pelvic region is compromised, due to 
uterine rupture or pelvic fracture. They also hypothesized that injury to the head of the fetus could occur from direct loading with the mother's pelvis or spine.

The goal of this study is to create a detailed computational representation of the pregnant occupant, incorporating the various bodily changes and anatomy of pregnancy, capable of simulating the dynamic response to impact. Specifically, the aim is to develop a realistic pregnant model with a fetus within uterus that could be used as a tool to predict the stresses and strains on the uterus and placenta, and to simulate the movement of the fetus within the uterus and its interactions with its surroundings.

\section{METHODOLOGY}

The research strategy in this study is to use an existing human female model and alter it to incorporate the various anthropometric and anatomical changes of pregnancy. A $5^{\text {th }}$ percentile female in her $38^{\text {th }}$ week of pregnancy is modelled. It has been shown that fetal /uterine size is independent of maternal stature [21]. Due to short limb length a $5^{\text {th }}$ percentile female must position herself far forward in a car to be able reach the various controls; by the $38^{\text {th }}$ week of pregnancy her abdominal size is at a maximum resulting in very close proximity to the steering wheel. Also in the later stages of pregnancy, the amount of amniotic fluid surrounding the fetus, which is thought to offer some degree of protection, is at a minimum and the fetus occupies the majority of the uterine volume. Hence a 38-week small pregnant women model represents a fuller term pregnancy with a large fetus and abdomen.

\subsection{Model development}

The three dimensional computational model is developed to tackle the complexity of a pregnant woman's anatomy by integrating a detailed multi-body representation of a fetus within a finite element uterus model. Then small female model of the software package MADYMO is modified to incorporate pregnant anthropometry. Finally fetus and uterus are incorporated to the modified female model. 
The multi-body fetus model comprises 15 rigid bodies representing the various anatomical regions of the fetus interconnected by kinematic joints. Hyperellipsoid surfaces are used to represent the different body segments. The dimensions of the head are taken from 38 week-old fetal biometric measurements based on ultrasound images as published [22]. The legs and arms [23] are derived from the bone data which are reported for 38 week-old fetus. For partially available data, for example, the trunk measurements, the published measurements [22] and new-born data [24] are used to determine the scaling factors and to calculate unknown trunk dimensions. A total fetal mass of $3.3 \mathrm{~kg}[25]$ is used, with the individual segment centre of gravity scaled positions proportionately from the TNO 9-month old child dummy [26]. The fetal spine is divided into four parts: lumbar, thoracic, and lower and upper cervical, represented by spherical joints with spring-damper constraints. The joint properties are scaled from the values found in the literature [27], [28], [29]. The hip, ankle and shoulder joints are also described using spherical joints, permitting three rotational degrees of freedom while the knee and elbow joints are represented by revolute joints, allowing one degree of freedom in the physical plane of rotation.

The finite element uterus model is developed in conjunction with the multi-body fetus model, with typical 38-week fetal dimensions and configuration controlling the dimensions of the uterus to give a snug fit around the fetus (Fig 2). This is also in agreement with the measurements of pregnant women collected in [30]. The uterus and placenta models are constructed within Solid Edge CAD software. The uterus and placenta were meshed using Hypermesh (Altair) by first meshing the inner surface of the uterus using quad elements, then mapping the elements to the outer surface to create the uterus, and mapping the corresponding elements of the placental outer surface to the inner surface of the uterus to create the placental elements. 


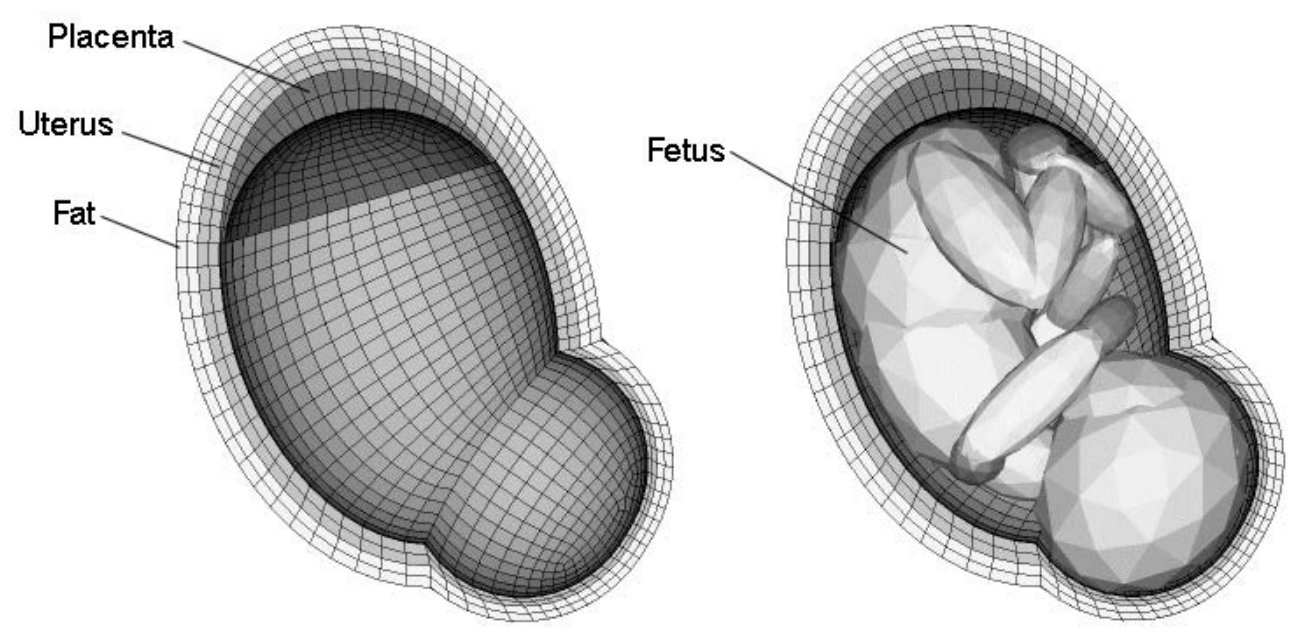

Fig 2 Cross-sectional view of the FE uterus and placenta with and without the multi-body fetus

Additionally, a $10 \mathrm{~mm}$ layer of fat is meshed around the outer surface of the uterus. The nodal coordinates and element configuration are then exported into MADYMO, where linear elastic 8 node solid elements are used for the three FE components. The material properties used for the uterus, placenta and fat are based on tissue tests $[20,31]$ and on other researchers' estimates [9] as follows: The uterus has a Young's modulus of $566 \mathrm{kPa}$, density of $1052 \mathrm{~kg} / \mathrm{m}^{3}$ and Poisson's ratio of 0.4 whereas the placenta has a Young's modulus of $63 \mathrm{kPa}$, density of $995 \mathrm{~kg} / \mathrm{m}^{3}$ and Poisson's ratio of 0.45 .

The placenta is generated as a discoid circular shape with a diameter of $185 \mathrm{~mm}$ and thickness of $20 \mathrm{~mm}$ at its centre. The uterine wall thickness is taken as $10 \mathrm{~mm}$ [10]. The resulting total mass of the uterus with placenta is $1.29 \mathrm{~kg}$.

The comparisons of the measurements of male and non-pregnant female populations from the published data and pregnant populations which are based on 48 anthropometric measurements of more than 100 pregnant women are published in Acar and Weekes [30]. The MADYMO female model is altered to represent the anatomy of a pregnant $5^{\text {th }}$ percentile female, using the anthropometric data collected from female volunteers in their final trimester of pregnancy. The changes 
are made to incorporate the sitting measurements of pregnant women to modify her abdominal chest and thigh profiles. The abdominal height and depth are taken as $242.6 \mathrm{~mm}$, and $334.3 \mathrm{~mm}$ respectively, whereas chest depth, hip breadth and thigh depth are $215.6 \mathrm{~mm}, 383.3 \mathrm{~mm}$ and $155.4 \mathrm{~mm}$ respectively.

To complete the pregnant occupant model, a finite element uterus with a multi-body fetus is integrated into the $5^{\text {th }}$ percentile female facet occupant model.

\subsection{Model validation}

Generally, physical or computational models of a human body are validated against experimental tests on soft tissues, isolated anatomical segments, whole cadavers or live human volunteers. The $5^{\text {th }}$ percentile female facet occupant model used in the development of the pregnant occupant model has been previously validated against impactor tests and small female PMHS tests [32]. For the pregnant occupant model, accurate response of the pregnant abdomen is required to be able to predict fetal injury risk. The pregnant occupant model is validated against rigid-bar impact and belt loading tests performed by Hardy et al [33]. Hardy et al developed forcedeflection abdominal corridors for a $50^{\text {th }}$ percentile male based dynamic testing of human cadavers, these corridors have since been equal-stress, equal velocity scaled to a $5^{\text {th }}$ percentile female by Rupp et al [20] in their development and validation of the MAMA2B ATD.

No real force deflection corridors are available for pregnant women due to lack of data. Hence it has been concluded that using the force deflection corridors of Hardy et $a l$ is a reasonable action to evaluate the response of the pregnant occupant model until new corridors specifically for pregnant women are available.

The test configurations described by Hardy et al are recreated using the occupant model. For the rigid-bar impact test a $25.4 \mathrm{~mm}$ diameter rigid bar weighting $48 \mathrm{~kg}$ is constructed and impacted into the abdominal region of the model at the

approximate height of the umbilicus at $6 \mathrm{~m} / \mathrm{s}$. The force-displacement response of the model to the $6 \mathrm{~m} / \mathrm{s}$ rigid bar loading case is shown in Fig 3 , plotted to compare with earlier researchers' results. 


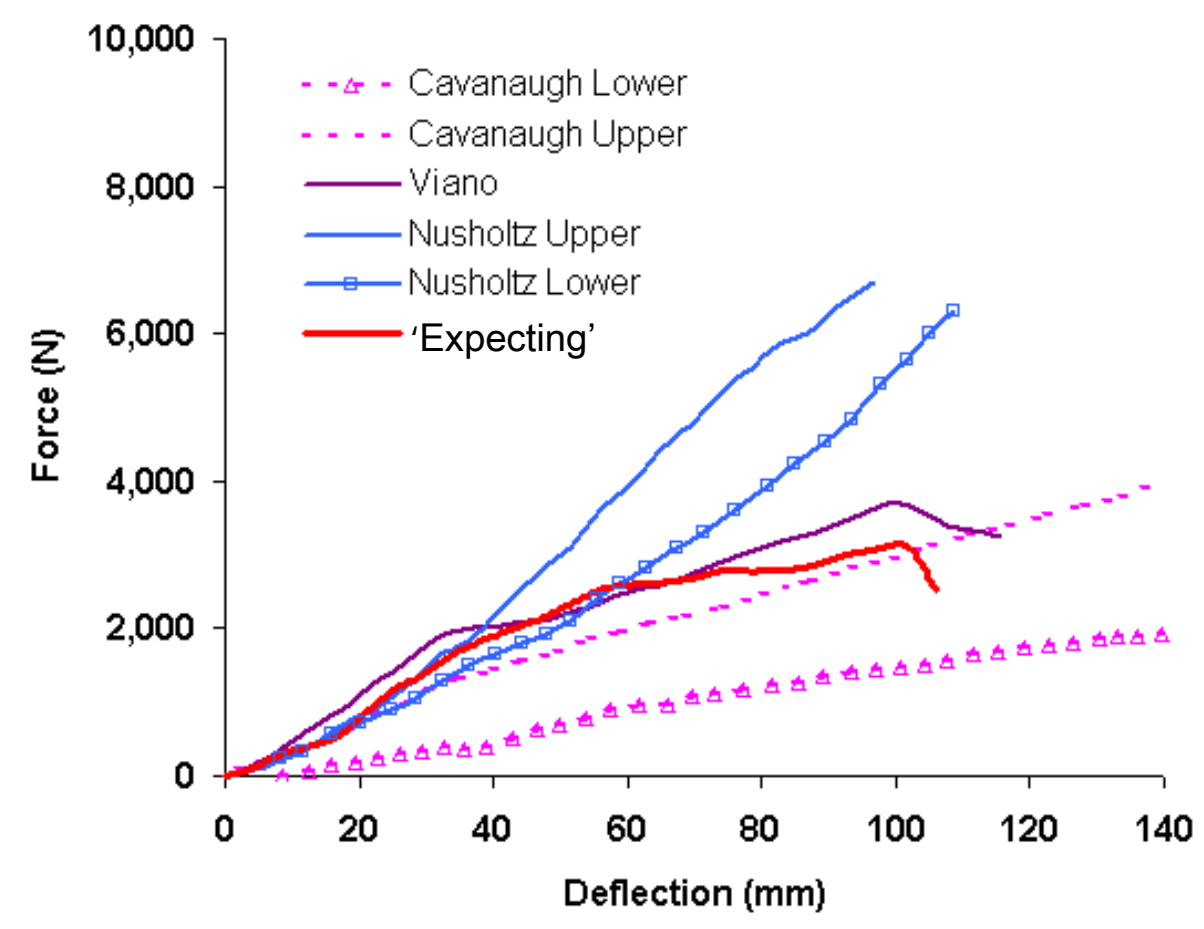

Fig 3 Abdominal response of the pregnant abdomen model to $6 \mathrm{~m} / \mathrm{s}$ rigid bar impact test compared with earlier researchers results

For belt-loading an FE belt section was initially wrapped around the pregnant abdomen, again at umbilicus height and was pulled across the pregnant abdomen at $3 \mathrm{~m} / \mathrm{s}$. For both cases force-displacement of the abdomen are recorded and found to be in good agreement with the experimental data, falling within the defined response corridors.

The force-displacement response of the model to the $3 \mathrm{~m} / \mathrm{s}$ belt-loading case is shown in Fig 4, plotted against the response corridor. 


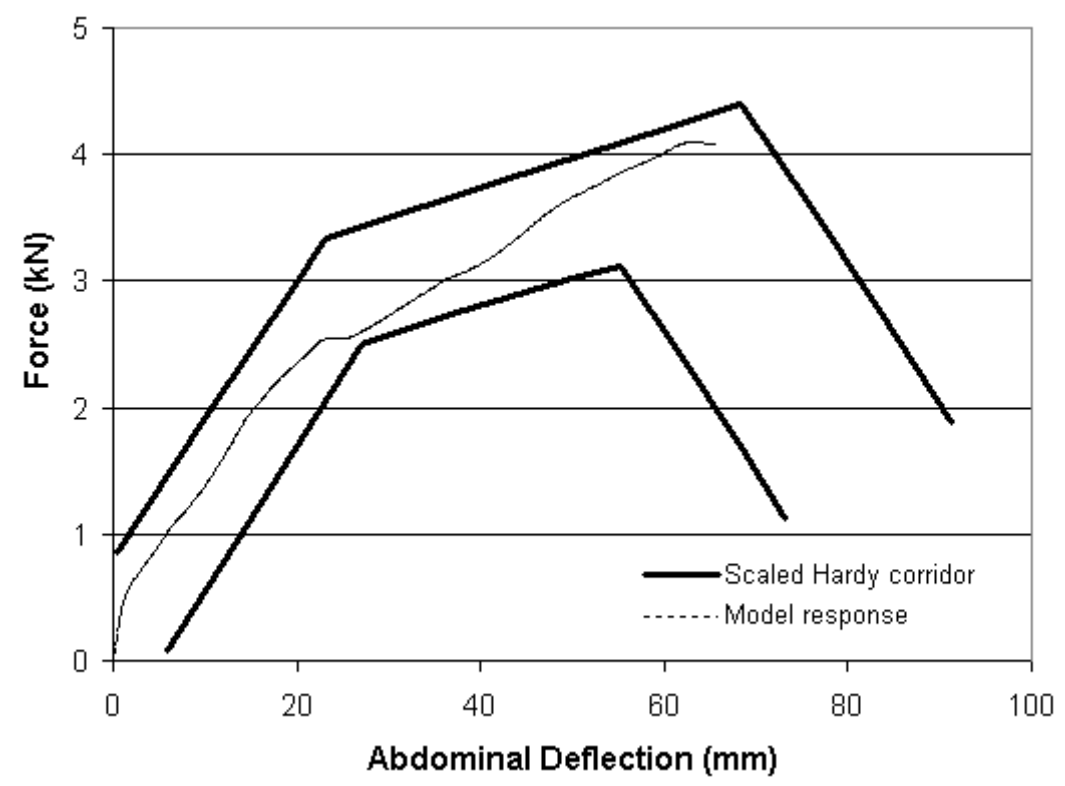

Fig 4 Abdominal response of the pregnant abdomen model to $3 \mathrm{~m} / \mathrm{s}$ belt loading compared against the response corridor.

\section{SIMULATIONS}

\subsection{Test Configurations}

A set of simulations are chosen to explore the affect of restraint use and crash severity on the response of the pregnant occupant as a vehicle driver to a frontal impact. Twenty one tests in total are run with crash speeds ranging from $15-45 \mathrm{kph}$ in $5 \mathrm{kph}$ steps. The recorded real acceleration pulses show that they all could be different for each crash even for the same-speed crashes [34], [35]. Some crashes may show high peak values of acceleration pulses with short duration whereas in some cases pulse duration could be much longer even for low speed crashes. Questionnaires filled in by more than 1000 pregnant women as part of the 3-year project 'Automotive design: Incorporating the needs of pregnant women' revealed that pregnant women drive older cars as well as new models. Simulations in this study aim to represent older cars as well as modern cars. While the airbags are 
standard in all modern cars, older cars may not have airbags, hence the investigations also included 3-point seatbelt only (no airbags) cases. Therefore for each crash speed 3 cases are run; unbelted, belted, and belted with an airbag. The acceleration pulses applied to the model are half-sine waves with $120 \mathrm{~ms}$ duration, the area under the curve being the change in velocity of the crash. The crash pulses used for the 7 speeds simulated are shown in Fig 5.

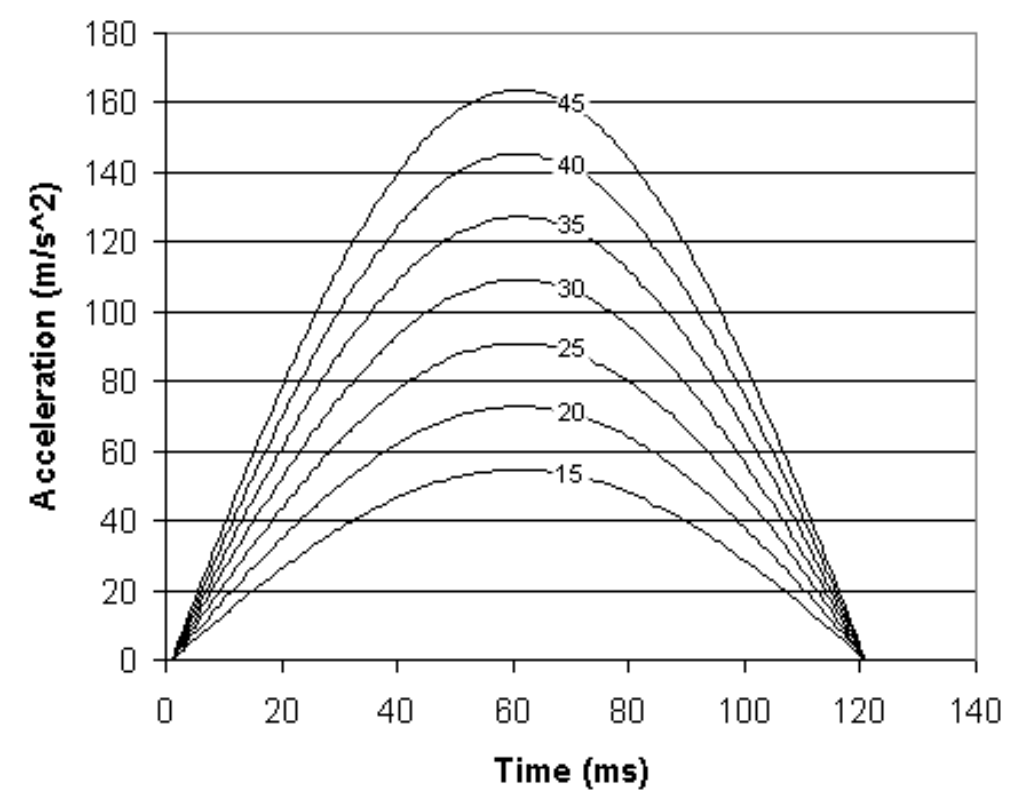

Fig 5 Acceleration pulses used as input for the crash simulations.

The model is placed within a typical vehicle interior consisting of a seat, vehicle floor, pedals, and steering wheel as shown in Fig 6 . The initial posture of the occupant in the driving seat representing the final trimester of pregnancy is based on seated anthropometic measurements by Acar and Weekes [30]. Seat height is set at $270 \mathrm{~mm}$ with a seat pan angle of $10^{\circ}$ to the horizontal. Seat back angle is set at $14.8^{\circ}$ past vertical. $\mathrm{H}$-point (sagittal plane hip joint centre) to ball of foot horizontal distance is $708 \mathrm{~mm}$ which defined the initial position of the vehicle pedals with respect to the seated occupant. The steering wheel is positioned relative to the uterus with a uterus to wheel overlap of $20 \%$, where the overlap is defined as the 
ratio between the vertical height of the uterus fundus (top of uterus) above the lowest point of the steering wheel rim, to the overall vertical height of the uterus. The horizontal distance between the steering wheel rim and the uterus is set at $45 \mathrm{~mm}$ in the initial position. Steering wheel tilt is $30^{\circ}$ from vertical.

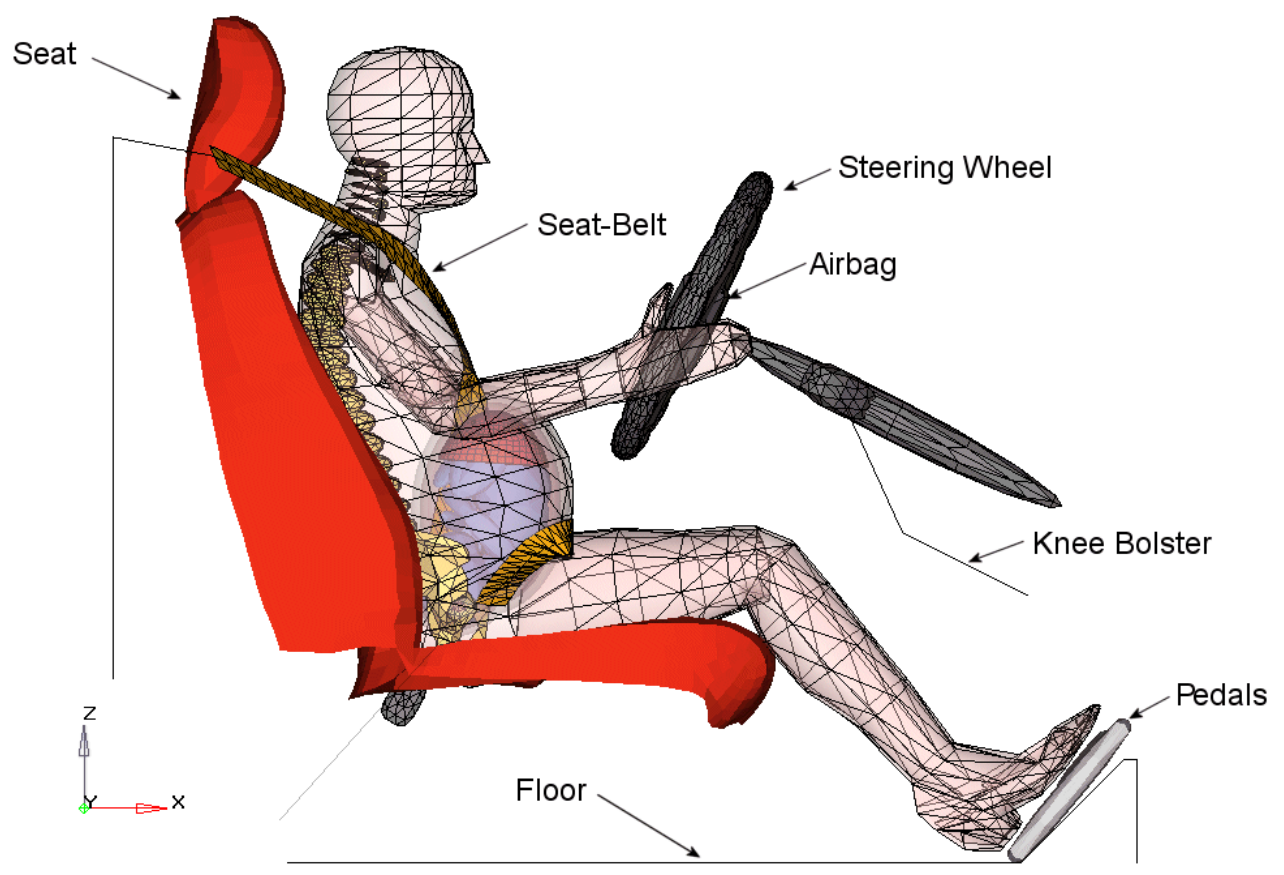

Fig 6 Simulation configuration; pregnant occupant model positioned within vehicle interior.

The restraint models consist of a three-point seatbelt and a driver airbag. The seat belt is made up of a lap and shoulder portion, with the width and thickness of the belt equal to $50 \mathrm{~mm}$ and $1 \mathrm{~mm}$ respectively. The sections of the belts that contact the occupant are modeled with non-linear 3-node triangular membrane elements, with generic belt properties provided within MADYMO. The standard MADYMO driver airbag model is utilized with the airbag set to trigger $15 \mathrm{~ms}$ into the acceleration pulse. The airbag is positioned at the centre of the steering wheel inline with the steering wheel tilt angle. 


\section{RESULTS}

\subsection{Strain and deformation of the uterus}

Maximum strains in the uterus over the area where the placenta is located are presented in Table 1, along with abdominal deformation due to lap-belt and steering wheel loading for the range of crash scenarios simulated. Maximum abdomen deformation due to lap belt loading is defined as the maximum value of the deformation displacements from the original shape, i.e. the maximum displacement of an FE node from its original location where the lap belt meets the abdomen. Similarly the maximum abdomen deformation due to steering wheel loading is defined at the location where the steering wheel meets the abdomen. It is usually on the anterior side of the uterus at placental location. These values are obtained by processing the MADYMO output via the post-processor, Hyperview v7. The deformations are extracted from the displacements of the nodes at the deformed regions.

Also shown for comparison are the predicted risks of fetal loss as determined by Klinich et al [4] for which the statistical analysis of 43 crashes involving pregnant occupants are used to calculate the probability of adverse fetal outcome for properly and improperly restrained occupants depending on the crash severity. All cases where the occupant was using a 3-point belt or a 3-point belt together with an airbag were considered to be 'properly' restrained, while 'improperly' restrained group included any case where only part of a 3-point belt had been used (i.e. just the lap portion or just the shoulder portion), together with cases where no belt had been used. The curves also included any occupant position, be it driver, front passenger or rear passenger and any impact direction; front, rear and side. In the simulated cases with the occupant model, all tests are frontal impacts with the occupant in a driver position and the improperly restrained cases are without a restraint of any form. 
Table 1 Simulation test range for frontal impacts for the three levels of restraint use.

\begin{tabular}{|c|c|c|c|c|c|c|}
\hline $\begin{array}{l}\text { Crash } \\
\text { Speed } \\
(k p h)\end{array}$ & Restraint use & $\begin{array}{c}\text { Risk of fetal } \\
\text { loss by } \\
\text { Klinich et al } \\
{[4]} \\
(\%)\end{array}$ & $\begin{array}{l}\text { Maximum } \\
\text { stain near } \\
\text { the placenta } \\
\text { by Moorcroft } \\
\text { et al [9] }\end{array}$ & $\begin{array}{l}\text { Maximum } \\
\text { strain in uterus } \\
\text { at placental } \\
\text { location }\end{array}$ & $\begin{array}{l}\text { Maximum } \\
\text { abdomen } \\
\text { deformation } \\
\text { due to lap-belt } \\
\text { loading } \\
(\mathrm{mm})\end{array}$ & $\begin{array}{l}\text { Maximum } \\
\text { abdomen } \\
\text { deformation due } \\
\text { to steering } \\
\text { wheel loading } \\
(\mathrm{mm})\end{array}$ \\
\hline 15 & Unrestrained & 41 & $0.233^{*}$ & 0.63 & $N / A$ & 41 \\
\hline 20 & Unrestrained & 54 & 0.366 & 0.78 & N/A & 50 \\
\hline 25 & Unrestrained & 68 & 0.446 & 0.89 & N/A & 69 \\
\hline 30 & Unrestrained & 78 & - & 0.95 & $N / A$ & 89 \\
\hline 35 & Unrestrained & 86 & 0.608 & 1.08 & $N / A$ & 106 \\
\hline 40 & Unrestrained & 91 & - & - & - & - \\
\hline 45 & Unrestrained & 95 & - & - & - & - \\
\hline 15 & 3-Point Belt & 11 & $0.155^{\star}$ & 0.13 & 20 & No Contact \\
\hline 20 & 3-Point Belt & 17 & - & 0.37 & 24 & 13 \\
\hline 25 & 3-Point Belt & 26 & 0.279 & 0.50 & 30 & 21 \\
\hline 30 & 3-Point Belt & 38 & - & 0.53 & 32 & 30 \\
\hline 35 & 3-Point Belt & 51 & 0.526 & 0.55 & 36 & 40 \\
\hline 40 & 3-Point Belt & 65 & - & 0.63 & 39 & 49 \\
\hline 45 & 3-Point Belt & 76 & 0.587 & 0.72 & 42 & 55 \\
\hline 15 & 3-Pt Belt \& Airbag & 11 & - & 0.24 & 18 & No Contact \\
\hline 20 & 3-Pt Belt \& Airbag & 17 & - & 0.38 & 22 & 7 \\
\hline 25 & 3-Pt Belt \& Airbag & 26 & 0.281 & 0.40 & 28 & 15 \\
\hline 30 & 3-Pt Belt \& Airbag & 38 & - & 0.41 & 31 & 25 \\
\hline 35 & 3-Pt Belt \& Airbag & 51 & 0.33 & 0.42 & 35 & 32 \\
\hline 40 & 3-Pt Belt \& Airbag & 65 & - & 0.49 & 38 & 38 \\
\hline 45 & 3-Pt Belt \& Airbag & 76 & 0.466 & 0.56 & 41 & 41 \\
\hline
\end{tabular}

For the belted and belted with an airbag cases the risk of fetal loss are the same for each given speed as Klinich et al [4] categorized 'properly' restrained occupants as anyone using a full 3-point belt with or without an airbag. For all three restraint types simulated, the risk of fetal loss, maximum strain, and maximum deformation due to lap-belt and steering wheel loading increases with increasing crash speed. The model becomes unstable at speeds above $35 \mathrm{kph}$ for the unrestrained tests due to 
the large deformations and strains. The peak strains in the uterus and peak deformation due to steering wheel loading are plotted against crash speed in Figures 7 and 8 respectively. Model response time histories are shown in Fig 9 for the three restraint cases at $35 \mathrm{kph}$.

The results show that, for any given speed, the unrestrained case leads to the highest strains in the uterus together with largest deformation due to contact between the abdomen and steering wheel. As can be seen in Fig 8 for all unrestrained cases, the peak strain in the uterus at placental location exceeds the threshold value of $60 \%$ indicating the likelihood of placental abruption.

The inclusion of the 3-point belt reduces the degree of steering wheel loading for each crash speed, and subsequently the maximum strain in the uterus. The belt limits the forward motion of the occupant at all speeds, as can be seen in Fig 9(b) for the $35 \mathrm{kph}$ case. For the $15 \mathrm{kph}$ case, impact with the steering wheel is prevented completely. The level of deformation due to contact with the steering wheel is again reduced at all crash speeds with the addition of an airbag, while deformation due to lap-belt loading remains fairly similar to the 3-point belt cases. The airbag reduces the forward motion and rotation of the upper body, resulting in this decrease of steering wheel contact, while the lower body's motion remains constrained by the lap-portion of the belt. At low speeds, 15 and $20 \mathrm{kph}$, higher strains in the area of the placenta are seen in the cases with an airbag than those with just a 3-pt belt, even though steering wheel contact is reduced. These strains are due to direct loading from the airbag on the upper portion of the uterus as the airbag inflates; at higher speeds this effect is less noticeable, due to the large levels of steering wheel contact with the uterus. 


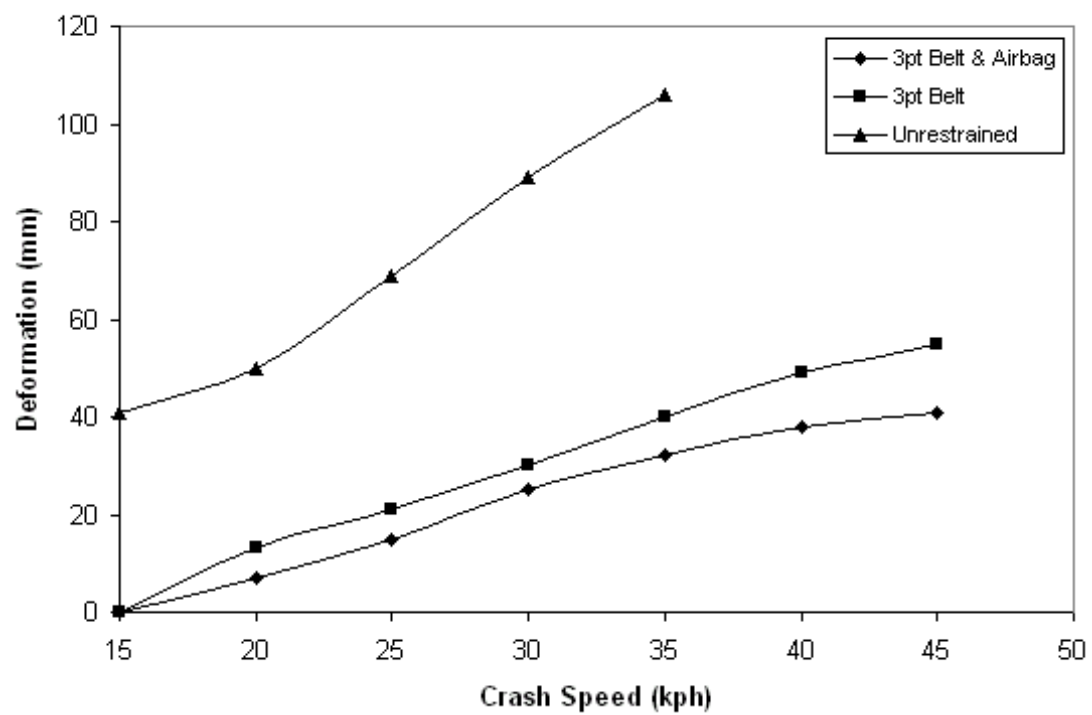

Fig 7 Maximum uterine deformation due to steering wheel loading for all test cases.

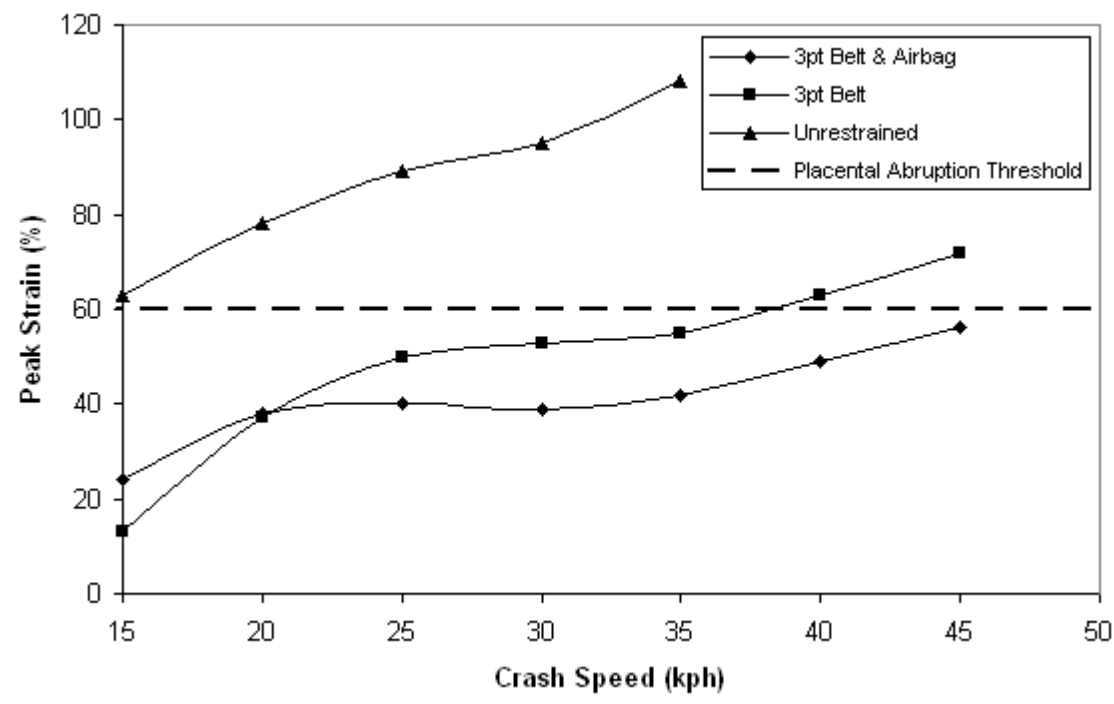

Fig 8 Peak strain in the uterus at the location of the placenta for all test cases shown against the $60 \%$ strain threshold for the occurrence of placental abruption. 
a) Unrestrained
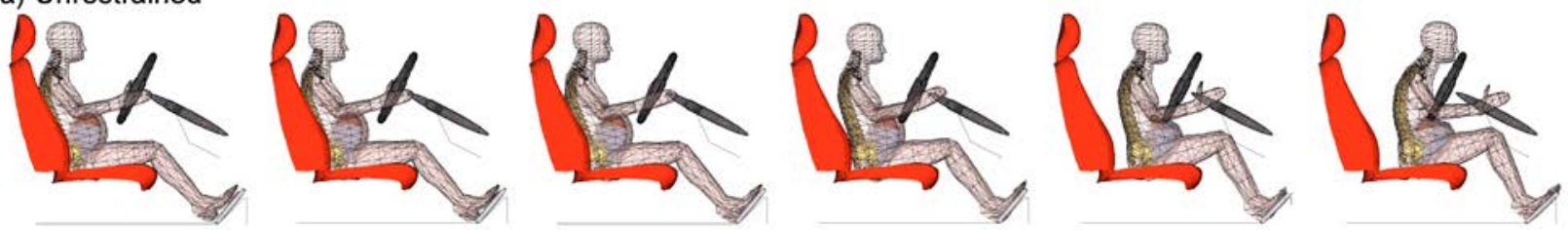

b) 3-Point Belt
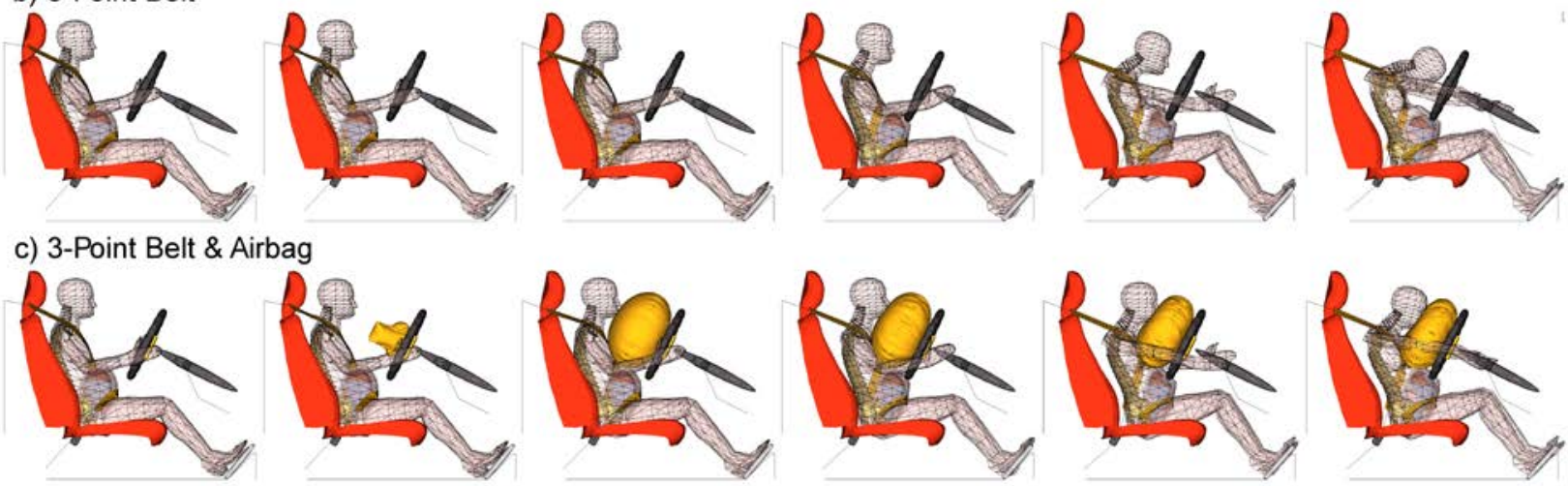

Oms
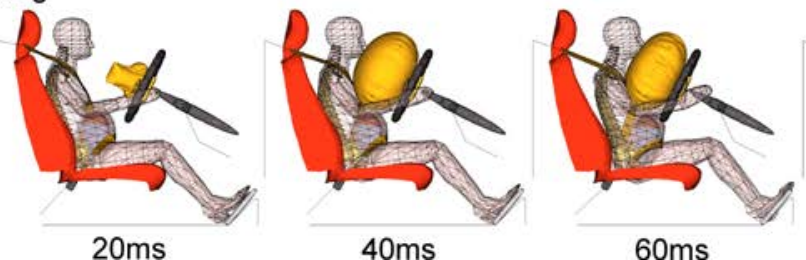

$60 \mathrm{~ms}$

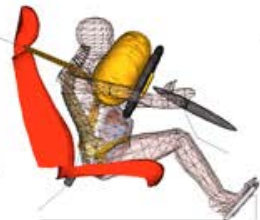

$80 \mathrm{~ms}$

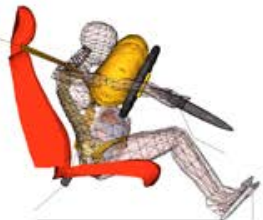

$100 \mathrm{~ms}$

Fig 9 Time histories of the pregnant occupant model for the three restraint cases in response to a $35 \mathrm{kph}$ impact.

\subsection{Fetal movement and loading.}

The 25kph, 3-point belt case is analyzed in detail to demonstrate the model's ability to predict fetal movement and loading. Fig 10 depicts the fetal kinematics over the course of the impact from 40 to 140ms; part of the lower spine, pelvis and sacrum of the mother are shown along with the pregnant uterus, placenta and fetus. Fig 11 shows the von Mises stress distribution in the uterus at two time steps: 60 and $100 \mathrm{~ms}$. Inertial affects on the fetus cause it to move forward relative to the mother as the 3-point belt restrains the occupant's motion. The fetus is forced against the anterior wall of the uterus causing stress concentration points from loading of the head, shoulder and pelvic regions (Fig 11,60ms). Stress is built up from lap-belt loading with the uterine wall being effectively sandwiched between the fetus and belt. The peak von Mises stress seen for this case was 245kPa. Fig 12 shows the peak stress due to lap belt and fetal loading for all restrained cases; in general peak 
stress is seen in the area where the pelvis region of the fetus contacts the anterior wall of the uterus. As strain at the placental location in the uterus is shown to exceed the threshold value for placental abruption for all unrestrained cases these are omitted from this analysis.

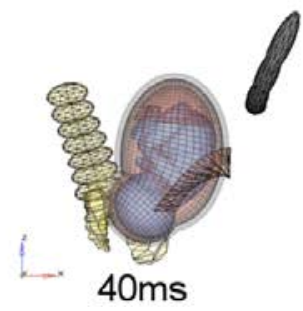

$40 \mathrm{~ms}$

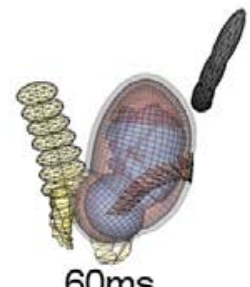

$60 \mathrm{~ms}$

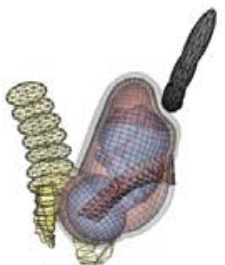

$80 \mathrm{~ms}$

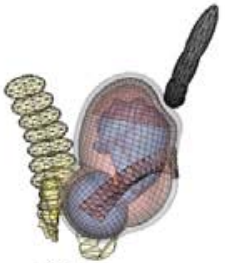

$100 \mathrm{~ms}$

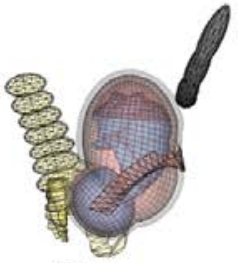

$120 \mathrm{~ms}$

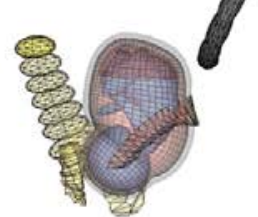

$140 \mathrm{~ms}$

Fig 10 Time history from 40 to $140 \mathrm{~ms}$ showing fetal movement during the $25 \mathrm{kph} 3$-pt belt test

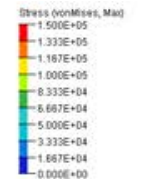

Fig 11Frontal view of isolated uterus at 60 and $100 \mathrm{~ms}$ showing the von Mises
due to fetal and lap-belt loading for the $25 \mathrm{kph} 3-\mathrm{pt}$ belt test.

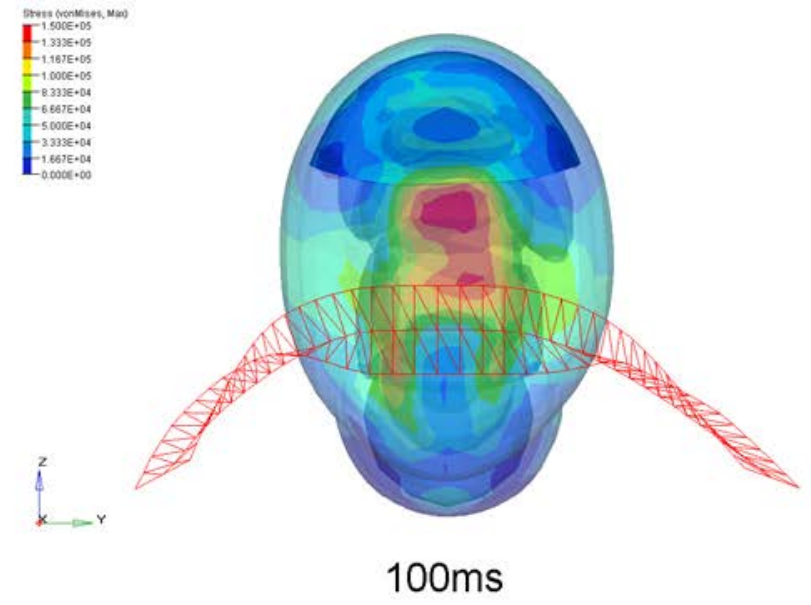

$100 \mathrm{~ms}$ 


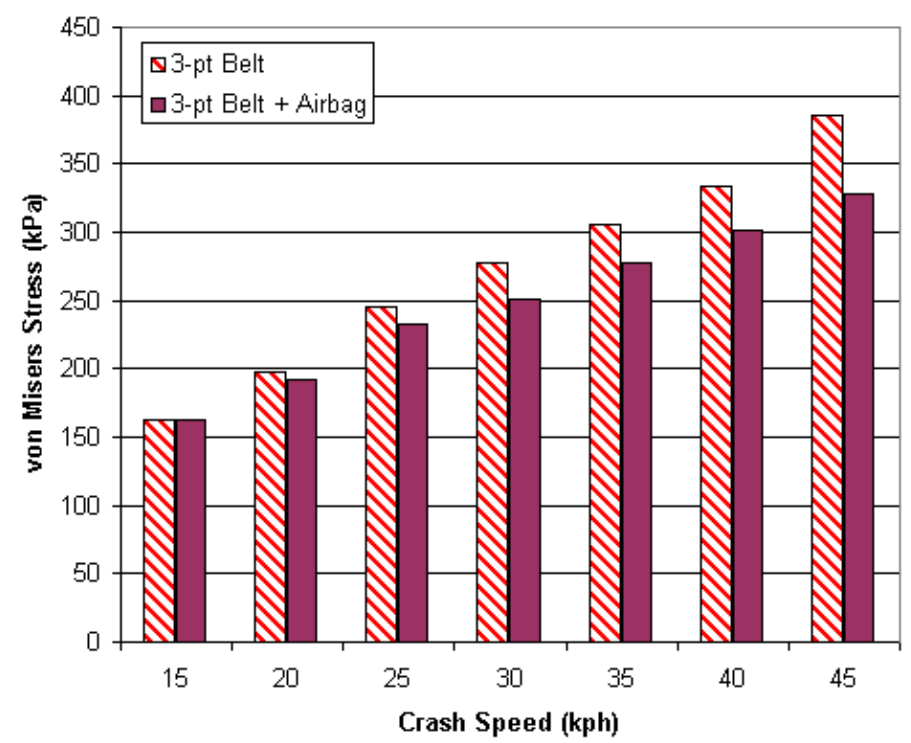

Fig 12 Peak von Mises stress in the uterus due to lap belt and fetal loading for all restrained cases.

\section{CASE STUDIES}

'Expecting', a computational pregnant occupant model representing a $5^{\text {th }}$ percentile female with a finite element uterus and a multi-body fetus at around the $38^{\text {th }}$ week of gestation, is generated at Loughborough University. The model is used to simulate a number of frontal impacts of increasing severity with three differing levels of occupant restraint.

Looking into the individual cases reported by Klinich et al [4], it was found that 4 of the cases were frontal impacts with the $36+$ weeks pregnant women as the driver. In one of these cases 3-point seatbelt was used, in the other three, 3-point seatbelt and airbag were used. These cases can be directly compared to the simulated cases, and are summarized in Table 2. Although GMP-010 has a higher crash speed than simulated, the $45 \mathrm{kph}$ case with a 3-pt belt resulted in a peak strain of $72 \%$, which is already above the threshold for placental abruption. The remaining three cases all with 3-pt belt and airbag resulted in no fetal complications. The peak strains at the placental location predicted by 'Expecting' for cases close to these were all below the $60 \%$ threshold. These results demonstrate the model's ability to predict fetal outcome based on the strain in the uterus. 
Table 2 Real world cases corresponding to simulated tests.

\begin{tabular}{|c|c|c|c|c|c|c|}
\hline Case No. & $\begin{array}{l}\text { Impact } \\
\text { Severity } \\
\text { (kph) }\end{array}$ & Restraint Use & $\begin{array}{c}\text { Gestational } \\
\text { Age } \\
\text { (weeks) }\end{array}$ & $\begin{array}{c}\text { Strain at placental } \\
\text { location predicted by } \\
\text { 'Expecting' } \\
(\%)\end{array}$ & $\begin{array}{l}\text { Accident } \\
\text { Outcome }\end{array}$ & $\begin{array}{l}\text { Predicted } \\
\text { Outcome }\end{array}$ \\
\hline GMP-010 & 71 & 3-pt belt & $36+$ & $72+$ & $\begin{array}{l}\text { Fetal loss, } \\
\text { placental } \\
\text { abruption }\end{array}$ & $\begin{array}{l}\text { Placental } \\
\text { Abruption }\end{array}$ \\
\hline GMP-025 & 28 & 3-pt belt \& airbac & $36+$ & 41 & No problems & No problems \\
\hline GMP-211 & 31 & 3-pt belt \& airbas & $36+$ & 41 & No problems & No problems \\
\hline GMP-027 & 13 & 3-pt belt \& airbas & $36+$ & 24 & No problems & No problems \\
\hline
\end{tabular}

\section{CONCLUSIONS}

'Expecting', the pregnant occupant model represents 38-week pregnant smallstature women who carry one fetus without abnormalities, in the most common posture with the placenta located in fundal region of the uterus as in majority of pregnancies. 'Expecting' is the first pregnant model realistically representing pregnant women with a multibody fetus within an FE uterus capable of predicting the stresses and strains on the uterus and placenta, as well as simulating fetal movement within the uterus. Furthermore, 'Expecting' is the first pregnant female model based on the sitting anthropometric details of pregnant women.

The later stage of gestation ( $38^{\text {th }}$ week) is important because overall the pregnant woman is larger, the uterus is larger, the fetus is much larger, and the uterus provides a snug fit around the fetus. This is the first study, which takes into consideration the fact that there is a solid body in the shape of a fetus within the uterus that affects the dynamic response of the model to impact.

As with any model of the human body the pregnant occupant model relies on available material data hence several assumptions and simplifications have been made during the development of the model. 'Expecting' is validated against rigidbar impact and belt loading tests. Force-deflection abdominal corridors which were scaled to a $5^{\text {th }}$ percentile female are used and 'Expecting' results are found to be in 
good agreement with the experimental data falling within the defined response corridors.

'Expecting' is also capable of investigating the consequences of the motion of the fetus within the uterus as a result of the impacts. The fetus model was developed using available data. Real accident outcomes are the only means of verifying the predictions by 'Expecting' including the fetus. Four real-life accident records are used to compare with the simulation results which demonstrate 'Expecting's ability to predict placental abruption.

$60 \%$ strain at placental location is accepted as a threshold value for placental abruption [20]. However $60 \%$ strain 'anywhere' on the uterine wall does not always mean $60 \%$ strain at the placental location. Therefore we have reported the strains in uterus at the placental location only.

In restrained cases, inertial affects on the fetus cause it to move forward relative to the mother and causing stress concentration points. In general peak stress is seen on the uterine wall where the pelvis region of the fetus contacts the anterior wall of the uterus. In such cases the maximum strain in uterus is caused by the fetal movement and interaction with the lap belt, since the shoulder belt and the airbag alleviate the steering wheel interaction; hence the strain at the placental location is generally lower than the maximum strain. In the unrestrained cases, in addition to the motion of the fetus, the strain in uterus is caused by the impact with the steering wheel causing high strains to occur at the placental location.

For the restrained cases, when there is no contact with the steering wheel the strain predicted by 'Expecting' poses no danger to the occupant as predicted by previous models representing different gestation levels. However in the cases that involve steering wheel interaction, 'Expecting' predicts high strains at placental location, which provides strong evidence that the fetus within uterus makes a difference. For the unrestrained cases unlike previous models, 'Expecting' predicts over 60\% strain at the placental location for all speeds considered.

The results from the series of simulations suggest the use of a 3-point seat belt with an airbag offers the greatest protection to the fetus for frontal crash impacts. It is 
hoped that the current model will raise awareness of the issues surrounding pregnant women as vehicle users, and will provide a useful tool for exploring the general response of the pregnant occupant and unborn baby in differing accident situations.

Overall, 'Expecting' is a significant step towards a more biofidelic model of a pregnant occupant with realistic dimensions and fetus within the uterus capable of simulating the dynamic response of pregnant women to impacts.

\section{ACKNOWLEDGEMENTS}

The "Expecting: A Pregnant Occupant Model" project (IMCRC05) has been funded by an EPSRC (Engineering and Physical Research Council, UK) research grant from the Innovative Manufacturing and Construction Research Centre. The authors would also like to acknowledge the support of the collaborating car manufactures, TNO Automotive for the use of MADYMO and consultant Obstetrician and Gynaecologist M. Griffiths.

\section{REFERENCES}

1 Haapaniemi, P. Women's highway deaths on the rise. Traffic Safety, 1996, 96, 6-11.

2 Pearlman, M.D. Motor vehicle crashes, pregnancy loss, and preterm labor. Int. J. Gynec. and Obstet., 1997, 57(2), 127-132.

3 Weiss, H.B. The epidemiology of traumatic injury-related fetal mortality in Pennsylvania, 19951997: The role of motor vehicle crashes. Accid. Anal. Prev., 2001, 33, 449-54.

4 Klinich, K.D., Schneider, L.W., Rupp, J.D., Eby, B., and Pearlman, M.D. Investigations of crashes involving pregnant occupants. UMTRI-99-200, 1999.

5 Snyder, R.G., Snow, C.C., Crosby, W.M., Hanson, P., Fineg, J. and Chandler, R. Impact injury to the pregnant female and fetus in lap belt restraint. Proc. $10^{\text {th }}$ Stapp Car Crash Conference, 1966, 249-59. 
6 Crosby, W.M., Snyder, R.G., Snow, C.C. and Hanson, P.G. Impact injuries in pregnancy. Am. J. Obstet. Gynec., 1968, 101(1), 100-110.

7 Pearlman, M.D., and Viano, D. Automobile crash simulation with the first pregnant crash test dummy. Am. J. Obstet. Gynec., 1996, 175, 977-981.

8 Rupp, J.D., Klinich, K.D., Moss, S., Zhou, L., Pearlman, M.D., and Schneider, L.W. Development and testing of a prototype pregnant abdomen for the small female Hybrid III small female ATD. Stapp Car Crash J., 2001, 45, 61-78.

9 Moorcroft, D., Duma, S., Stitzel, J., and Duma, G. A finite element and multi-body model of the pregnant female occupant for the analysis of restraint effectiveness. SAE 2003-01-0157,.

10 England, M.A., A colour atlas of life before birth - Normal Fetal Development, 1983, Wolfe Medical Publications Ltd, 1983

11 Standing, S., Editor-in-chief. Gray's Anatomy 39 ${ }^{\text {th }}$ Ed. Elsevier Churchhill Livingstone. 2005.

12 Fried, A.M. Distribution of the bulk of the normal placenta. Review and classification of 800 cases by ultrasonography. Am. J. Obstet. Gynec., 1978, 132(6), 675-680.

13 Pepperell, R.J., Rubenstein, E., and Maclsaac, I.A. Motor-car accidents during pregnancy. Med. J. Aus., 1977, 1, 203-205.

14 Bunai, Y., Nagai, A., Nakamura, I., and Ohya, I. Fetal death from abruptio placentae associated with incorrect use of a seatbelt. Am. J. For. Med. Path., 2000, 21(3), 207-209.

15 Crosby, W.M., and Costiloe, J.P. Safety of lap-belt restraint for pregnant victims of automobile collisions. New Eng. J. Med., 1971, 284, 632-636.

16 Agran, P.F., Dunkle, D.E., Winn, D.G., and Kent, D. Fetal death in motor vehicle accidents. Annals of Em. Med., 1987, 16(12), 1355-1358.

17 Goodwin, T.M., and Breen, M.T. Pregnancy outcome and fetomaternal hemorrhage after noncatastrophic trauma. Am. J. Obstet. Gynec., 1990, 162(3), 665-671.

18 Pearlman, M.D., Tintinalli, J.E. and Lorenz, R.P. A prospective controlled study of outcome after trauma during pregnancy. Am. J. Obstet. Gynec., 1990, 126(6), 1501-1510.

19 Pearlman, M.D., Tintinalli, J.E., and Lorenz, R.P. Blunt trauma during pregnancy. New Eng. J. Med., 1990, 323(23), 1609-1613. 
20 Rupp, J.D., Schneider, L.W., Klinich, K.D., Moss, S., Zhou, J., and Pearlman, M.D. Design, development, and testing of a new pregnant abdomen for the Hybrid III small female crash test dummy. UMTRI-2001-07, 2001.

21 Klinich, K.D., Schneider, L.W., Eby, B., Rupp. J., and Pearlman, M.D. Seated anthropometry during pregnancy. UMTRI-99-16, 1999.

22 Snijders, R.J.M., and Nicolaides, K.H. Fetal biometry at 14-40 weeks gestation. Ultrasound Obstet. Gynec., 1994, 4(1), 34-48.

23 Jeanty P, Rodesch F, Delbeke D, Dumont JE Estimation of gestational age from measurements of fetal long bones. J Ultrasound Med. 1984 Feb;3(2):75-9.

24 BSI. Body measurements of boys and girls from birth up to 16.9 years, BS7231: Part 1. British Standards Institute, 2 Park Street, London, UK, 1990.

25 Romro, R., Pilu, G., Jeanty, P., Ghidini, A., and Hobbins, J.C. (eds). Prenatal Diagnosis of Congenital Anomalies. Appleton and Lange, Norwalk, 1983, 323-324.

26 MADYMO DATABASE MANUAL. TNO P Child Dummies (P3/4, P3, P6, P10 and P1 $1 / 2$ ). TNO Automotive, 2003, 297-310.

27 De Jager, M K J Mathematical head-neck models for acceleration impacts. PhD Thesis, Technical University of Eindhoven, 1996.

28 Prasad P and King A I An experimentally validated dynamic model of the spine $J$ Appl Mech 41:545-550, 1974.

29 Schultz A B, Warwick D N, Berkson M H, Nachemson A L Mechanical properties of human lumbar spine motion segments, Part1. Responses in flexion, extension, lateral bending and torsion $\mathrm{J}$ Biomech Eng, 101:46-51.

30 Acar, B.S., and Weekes, A.M. Measurements for pregnant driver comfort and safety. Int. J. Veh. Des., 2006 42(1), 101-118.

31 Pearsall, G.W., and Roberts, V.L. Passive mechanical properties of uterine muscle (myometrium) tested in vitro. J. Biomech., 1978, 11, 167-176.

33 MADYMO HUMAN MODELS MANUAL. Facet Occupant Models. TNO Automotive, 2005, 22153. 
33 Hardy, W.N., Schneider, L.W., and Rouhana, S.W. Abdominal impact response to rigid-bar, seatbelt, and airbag loading. Stapp Car Crash J., 2001, 45, 1-32.

34 A Kullgren, A Lie and C Tingvall, Crash pulse recorder - validation in full scale crash tests, Accid Anal and Prev, 199527 (5) 717-727

35 M S Varat and S E Husher, Crash pulse modelling for vehicle safety research, $18^{\text {th }}$ ESV Conference, Nagoya, Japan, 2003. 